\title{
Environmental Problems of Use of Foreign Direct Investment Projects in China
}

\author{
Jun Li \\ School of Management \\ Hubei University of Chinese Medicine \\ Wuhan, China
}

\author{
Li Ding \\ Wu Han Huitong Pharmaceutical Limited Company \\ Wuhan, China
}

\begin{abstract}
With the acceleration of the globalization of the world economy, deepening of China's reform and opening up, improvement of economic development level and living quality, demand for environmental quality has been continuously enhanced. With the acceleration of the process of industrialization and urbanization in China, the relationship between foreign direct investment (FDI) and environmental pollution has attracted much attention. China has made remarkable achievements in absorbing FDI over the past 30 years since reform and opening up. Undeniably, FDI has promoted the growth of China's economy, improved labor productivity, effectively facilitated the development of export, popularized environmental technology, and promoted the environmental protection consciousness of citizens and so on. However, FDI is a "double-edged sword". With the gradual introduction of FDI, its industry gradually shift, so a large part of the pollution-intensive industries (Pollution Intensive Industries, referred to as PIIs) also gradually transferred to China, which also exerts negative effects on environmental protection. Waste water, waste gas and solid waste generated by pollution-intensive industries greatly damages the ecological environment and poses a serious threat to the people's health, which causes obstacles to process of sustainable development in China and affects the public health of the whole society.
\end{abstract}

Keywords-Foreign Direct Investment; environmental pollution; environmental protection

\section{INTRODUCTION}

International direct investment (FDI) is one of the main forms of modern capital internationalization. According to the definition of the International Monetary Fund, FDI refers the investment behavior that the natural person, legal person or other economic organization of a country contributes, either alone or jointly, in the territory of other countries to set up new enterprises, or increase the capital to expand the original enterprise, or acquire the existing enterprises, and have effective right of management and control. The amount of foreign direct investment China use significantly grows in recent years, and the economic benefits brought about is also obvious to all. But is it really good without harm?

\section{THE CURRENT SitUATION OF USE OF FOREIGN DIRECT INVESTMENT IN CHINA AND ENVIRONMENTAL POLLUTION}

\section{A. Development Process of Use of Foreign Direct Investment in China}

Over the past 30 years of China attracting foreign investment, an overall trend is a large amount of foreign investment continues come into China and the scale of investment continues to expand. It maintains a rapid growth rate. China's actual use of foreign investment in 2015 alone reached 781.35 billion yuan, an increase of $6.4 \%$; in 2016 , amount of foreign investment China actually used is 813.22 billion yuan, an increase of $4.1 \%$. But in fact, development process of China's use of foreign direct investment is adjusted accompanied by changes in the domestic economic environment and foreign economic policy, which obviously presents the following four development stages:

- Initial stage (in 1979-1986): Reform and opening up can be regard as the beginning of China's attracting foreign investment, and then China basically formed a policy framework for the introduction of foreign investment, initially forming the development pattern of overall opening up along the coast and Yangtze River.

- Stage of stable development (in 1987-1991): In October 1986, the State Council promulgated the Provisions on Encouraging Foreign Investment. As the policy of foreign investment was gradually relaxed and the investment environment was further improved, the investment rate of foreign investors in China was gradually accelerated.

- Stage of Rapid growth (in 1992-1997): In the spring of 1992, Comrade Deng Xiaoping's speech in the South remove the obstacles on further acceleration of the reform and opening up and more use of foreign direct investment. Afterwards, Policy on China's attracting foreign direct investment enters the stage of comprehensive deepening. Fields involved in foreign direct investment in China further expand, and the investment structure is optimized. 
- Adjustment stage (in 1998-2007): From the second half of 1995, China began to make a lot of policy adjustments on the introduction of foreign investment, strategic focus on the use of foreign direct investment transit from the number to quality, efficiency and optimization of structure. Thus it can adapt to adjustment of China's foreign investment policy and foreign direct investment in China has entered a stage of adjustment and slow and stable development. Because the abolition of some preferential policies, in 1996, the number of foreign investment projects in China and the amount of foreign investment declined dramatically. Influenced by Asian financial crisis and foreign policy adjustments in Southeast Asian countries, the amount of foreign investment actually used by China in 1999 reduced significantly again. In 2001, China joined the WTO. After the adjustment of policy, development of foreign direct investment show the development trend of significant improvement in the quality and efficiency, and the structure is more reasonable.

- Present stage (2007 to now): In December 2010, China unified the additional system of urban maintenance and construction and education fee for foreign-funded enterprises and individuals, and then "super-national treatment" in the tax policy enjoyed by foreign-funded enterprises ended. China guides the foreign-funded enterprise for adjustment of economic structure by welcoming the overseas investment in the fields of high-end manufacturing, high-tech industry, modern service industry, new energy and energy saving and environmental protection industries, and restricting the investment from companies with heavy pollution and high energy consumption and capacity. The structure of using foreign direct investment is continuously optimized. [2]

From the perspective of policy on the introduction of foreign direct investment in China, with the development of the times, the quality and quantity of foreign investment introduced in China are gradually optimized, and its impact on the environment is also improved. The policy adjustment of foreign direct investment makes foreign direct investment pay more attention to quality improvement. Therefore, environmental pollution is gradually reduced, mainly reflecting in transformation of foreign direct investment projects and the introduction of environment-friendly industries. So the use of foreign direct investment has been inseparable with environmental issues.

\section{B. Current Situation of Environmental Pollution in China}

1) Current situation of water pollution: China's water resources are facing a grim situation. On the one hand, China's per capita fresh water resources are too low, and spatial and temporal distribution of fresh water resources is uneven. On the other hand, phenomenon of water resources waste in China is widespread. Due to low water use efficiency and serious water pollution, water resources have become the scarce resources of economic and social development in China. According to statistics, China's total discharge amount of wastewater in 2015 is 71.62 billion tons, among which the industrial wastewater discharge is 20.59 billion tons and urban sewage discharge is 51.5 billion tons. China's environmental status bulletin in 2014 shows that China's surface water is generally polluted; at the same time, the situation of groundwater is not optimistic, since the groundwater level continues to decline and pointlike pollution trends emerges, which further exacerbated the contradiction between water supply and demand. In 2004, water quality monitoring was carried out in 968 monitoring sections of state-controlled surface water (points) of 423 major rivers and 62 key lakes (reservoirs) in China. I, II, III, IV, V and VI account for 3.4\%, 30.4\%, 29.3\%, 20.9\%, 6.8\%, $9.2 \%$ respectively, with the main pollution indicators of the chemical oxygen demand, total phosphorus and five biochemical oxygen demand. China's water pollution owns the following characteristics:

- Wide scope of water pollution: The investigation report in 1998 pointed out that the seven major rivers (Yangtze River, the Yellow River, the Pearl River, the Huaihe River, the Liaohe River, the Haihe River and the Songhua River) and the Taihu Lake, Chaohu Lake and Dianchi Lake were seriously affected by water pollution, leading $63 \%$ of them unsuitable to be the source of drinking water.

- Water pollution accidents occur frequently: Preliminary statistics show that from 1997 to 2014, the total number of industrial pollution accidents occurred in China is 1.1838 million, of which 6403 cases are wastewater pollution accidents, accounting for $54.1 \%$ of total pollution accidents. The most recent water pollution accident occurred on the evening of November 23, 2015 in Xihe county Longnan City Gansu Province. The overflow wells of tailings pond in concentrator plant of Gansu Longxing Antimony Industry Limited Liability Company leaked and then the pollutants, antimony spread along the riverway. Pollutants threaten the water supply security of Gansu, Shaanxi and Sichuan provinces.

- Great demand for investment in water pollution control: Water pollution control is a long and arduous task. In order to ensure that by 2020, urban and rural residents' drinking water can achieve safety or basic safety, water pollution control still requires a huge investment for improvement.

2) Current situation of air pollution: In recent years, China's air pollution prevention and control work achieved great success due to continuous investment and governance, and increasing intensity. However, owing to diversified climate conditions and some other reasons in China, the governance task of air environment is arduous, facing a rather severe situation. In 2014, in the 161 prefecture-level 
cities and above adopting the air quality monitoring with new standard nationwide, annual average of air quality in 16 cities reached the standard while that of 145 cities were excessive. There were 470 cities (districts and counties) where precipitation monitoring was carried out in China, among which the proportion of city with acid rain reached $29.8 \%$, so the average frequency of acid rain reached $17.4 \%$. [3]

Air pollution situation in China mainly presents the following characteristics:

- That Pollution of nitrogen oxides and sulfur dioxide are the representative is the main feature of air pollution in China. National emissions of sulfur dioxide are 1974.44 million tons. National emissions of nitrogen oxides are 20.78 million tons. National emissions of smoke (dust) are 17.48 million tons. . .

- The degree of air pollution in China has significant differences in space. In space, the overall degree of pollution in the northern city is more severe than the southern cities, especially in winter.

3) Pollution status of industrial solid waste: With the increase of solid waste management, situation of industrial solid waste pollution has improved. According to the latest statistics, in 2014, general industrial solid waste production in China reached 3.26 billion tons, with the comprehensive utilization of 2.04 billion tons, storage capacity of 450 million tons, the disposal amount of 800 million tons, dumping capacity of 594,000 tons. The comprehensive utilization rate of the national general industrial solid waste is $62.1 \%$. National industrial hazardous waste production is 36.353 million tons, the comprehensive utilization of 20.618 million tons, the storage capacity of 6906,000 tons, the disposal capacity of 9.29 million tons; the national industrial hazardous waste comprehensive utilization rate is $81.2 \%$. "Annual Report on Solid Waste Pollution Prevention in Large and Medium City of China in 2016" issued by the Ministry of Environmental Protection pointed out that according to the information of waste pollution prevention and control released by 246 large and medium cities of our country in 2015 , the general industrial solid waste capacity is 1.91 billion tons, industrial hazardous waste capacity is 28.018 million tons, the amount of medical waste is about 689,000 tons, the amount of domestic waste generated about 185.64 million tons.

This shows that environmental problems in China are very serious, especially industrial pollution accounting for a large proportion. Foreign direct investment projects invest mostly in the industry, especially some chemical industry with environmental pollution. This is also in line with the practice of some developed countries that transfer pollutionintensive industries to the developing countries. Thus, it has to be said that foreign direct investment projects have an important link with the environment of host countries.

\section{RELATIONSHIP BETWEEN USE OF FOREIGN DIRECT INVESTMENT AND THE ENVIRONMENT}

\section{A. "Environmental Shelter" Hypothesis -Foreign Direct Investment Jeopardizes the Chinese Environment}

Walter and Ugelow proposed the hypothesis of "pollution shelter" in 1979. The theoretical basis of this hypothesis includes the $\mathrm{H}-\mathrm{O}$ theory of environmental elements. The level of economic development of a country and income level will affect the extent of environmental protection. So the distribution of gift of environmental factors is not the same in developed and developing countries. In developing countries with low environmental protection level, environmental factors are relatively abundant while in developed countries with high environmental protection level, environmental elements are relatively scarce. Developing countries often make full use of their more affluent environmental elements to develop pollution-intensive industries. Meanwhile, in developed countries with the relatively high environmental protection level, high-polluting industries are gradually migrated to developing countries inevitably. As a result, developing countries will gradually become the world's pollution shelter. Due to the increasingly stringent environmental standards of the developed countries, enterprises operating pollutionintensive products must bear the higher cost of pollution control, especially in the industry of petroleum processing, paper production, metal smelting and so on. The cost of pollution control almost account for $1 / 4 \sim 1 / 3$ of the total cost of the enterprise. As a result, many multinational companies will slowly transfer these high-polluting industries to developing countries. China is the largest developing country, so we can see that China's absorption of foreign direct investment cannot avoid the negative impact on the environment.

\section{B. Foreign Direct Investment Brings Technology and Funds that Improve the Domestic Environment}

Foreign direct investment will introduce advanced production technology, efficient management tools, environmental protection facilities and materials to improve input and output efficiency, and promote the application of cleaner production and implementation of environmental management, so as to improve the quality of ecological environment in the host country. For example, multinational companies usually own more money, more advanced technology and management talent. In order to continue their own advantages, multinational companies tend to increase the investment in research and development of improving resource utilization and reducing emissions. This makes multinational companies bring advanced production technologies and equipment to the host country when making foreign direct investment.

At the same time, foreign direct investment often leads to the expansion of domestic production scale and the improvement of national income level. With the economic growth and the gradual increase in people's income, environmental quality will eventually be gradually improved. Because the environmental quality is a high-end 
consumer goods, with the gradual increase in the income level, needs for environmental quality will increase substantially. Moreover, people not only simply have the willingness to consume, but also have the ability to increase the protection and management of the environment, so the environmental problems will be significantly improved.

Although foreign investment projects are both beneficial and harmful to the environment, in my opinion, it is far more harmful than beneficial to the environment. Capital is profit-driven, so the governance of environment is far more difficult than polluting the environment and the cost is much more. Therefore, it is ridiculous and ludicrous to rely on the responsibility of foreigners to protect the environment. Only a reasonable system can guarantee our protection of the environment. Hence, we cannot expect the self-restraint of foreign businessmen. Although sometimes they show the beneficial side to the environment, we should focus more on their adverse effects on the environment. The following is a detailed analysis on foreign direct investment and environmental pollution.

\section{ANALYSIS ON THE CAUSES OF ENVIRONMENTAL POLLUTION CAUSED BY FOREIGN DIRECT INVESTMENT}

\section{A. Government Failure}

Since the reform and opening up, the Chinese government is getting more concerned about the protection of the environment, and a series of environmental policies and regulations has been developed comprehensively and systematically with environmental management agencies gradually becoming large, but the momentum of environmental pollution is still difficult to suppress fundamentally. This shows that in the process of environmental governance in China, phenomenon of "government failure" is obvious. In our country, the most prominent problem of "government failure" is that local governments do not fully implement the policies of the central government, mainly due to the uncoordinated and conflicting interests of the central government and local governments. Decision makers are concerned about whether the environment is improving, whether pollution is reduced, while local government agents at all levels are concerned about the promotion of their own administrative positions. As attracting foreign direct investment will lead to rapid growth of the local economy in the short term, as well as solve part of the employment problem, so largely using of foreign direct investment is not surprising. Because local officials are more aware of the "unspoken rule" of position promotion which takes economic growth as the decisive factor while other factors as secondary factors, the industry chosen by foreign direct investment is relatively less concerned about, thus resulting in the possibility of environmental destruction.

\section{B. Market Failure}

1) External problems: Externality refers to the phenomenon of market failure that impact of an economic entity on the welfare of other economic entities is not fully reflected in the market transactions. [5]

For example, a foreign company may pollute the river because it discharges dirty water, or pollutes the air because it discharges dust. This behavior has caused loss to nearby people and the whole society, but emitter of the pollutant do not bear any responsibility for these adverse effects. At this time the private cost of the enterprise is less than the social cost, which makes the social optimal amount lower than the market optimal amount.

2) Definition of property rights: First one is property rights of resources and environment is not clear. Mainstream economics believes that property rights must be clearly defined; otherwise it will cause legal disputes, so that uncertainty of ownership will occur, which combats people's positivity of investment in resources, preservation and management. In the condition that the private property right is not clearly defined, trade liberalization and FDI will accelerate the destruction of environmental resources in developing countries and thus pose a further threat to the global environment.

3) Information asymmetry: Information asymmetry refers to the fact that some participants in the market have more information, while others have less information. [5]

Information asymmetry will cause both moral hazard and adverse selection. Escaping pollution prevention is the most important manifestation of moral hazard in the utilization and protection of environmental resources. As the pollution-intensive industries and the green industry has not been clearly distinguished, it is the effect of adverse selection that foreign investment is more willing to invest in the industry that may lead to punishment but with the higher rate of return.

4) Issues on public resource: Goods with nonexclusivity and non-competitive are called public goods. Environmental pollution itself can be regarded as bad public goods, and a person suffering from the air pollution does not reduce the degree of another victim. The resources provided by the environment contain a lot of public goods, such as clean air, clean water and so on. Since no person will pay for the services provided by these environments, there is a large number of "free rides", leading to the decline in the quality of environmental services, which mainly reflect in the deterioration of the ecological environment.

\section{Public Awareness of Environmental Protection is Weak}

It is not enough to rely only on the country's environmental management and the self-discipline of each enterprise without the support and participation of residents. For a long time, public participation in environmental protection in China is not very optimistic, which can be seen from the "livelihood index of public environmental protection in China"1. In 2013, the index score was 69.5

"China's public environmental protection and livelihood index", or "people's livelihood index" for short, is the first domestic environmental index guided by the State Environmental Protection Administration, and 
points, maintaining a stable situation compared with 2012 (68.1 points) and 2011 (69.1 points), but it still haven't broken seven. Currently, the large environmental environment and public environmental drive has not yet reached the point where transformation can come into being. This data reflects that Chinese citizens' concern about the environmental is not high, enthusiasm of participation is not strong, and the public environmental protection proactivity is poor. At present, although public awareness of environmental protection and knowledge on environmental protection in China has improved to some degree, the ability to participate in environmental protection is still poor with "all bark and no bite" as the majority. What is worth of more attention is that the vast majority of the public do not know how to participate once they meet the specific environmental problems.

\section{SUGGESTIONS ON ENVIRONMENTAL POLLUTION CAUSED BY FOREIGN DIRECT INVESTMENT}

\section{A. Optimize Investment Structure}

It embodies in the two aspects. The industrial and regional orientation of foreign investment should be gradually mediated. Fields and projects of foreign investment should be divided into four categories of encouragement, restriction, strict restriction and prohibition from the perspective of environmental protection, which means prohibiting the project, technology and equipment that seriously pollute the environment without effective governance, restrict the introduction of projects that may cause serious environmental pollution or are very difficult to govern and encourage the introduction of projects that can bring advanced technology and have a positive impact on improving the environment.

In the regional issues, access principle of foreign investment in the western and remote areas should be appropriately relaxed, and we should make full use of foreign direct investment to stimulate the balanced development of domestic economy, which can achieve economic growth while respect the nature.

\section{B. Complete the Environmental Law, and Increase Law Enforcement}

To achieve the sustainable development of China's economy, the laws and regulations must be improved. The environmental laws and regulations should actively consider the issue of development of foreign direct investment, and laws and regulations on foreign direct investment should also consider the issue of sustainable development. The environmental protection issue should be carefully considered when signing and modifying bilateral investment agreements. There should be special environmental clause in the agreement.

organized by China Environmental Culture Association, known as the "barometer" of Chinese public environmental awareness and behavior.

\section{Establish Emissions Trading System}

Discharge permit means that only enterprises with the permit can discharge pollutants. It sets the number of permissible emissions, so the amount beyond the prescribed quantity will be subject to heavy penalties and the discharge permit can be traded. It can not only control the total pollution of the society within the scope of government permits, but also promote enterprises to improve their ability of clean production. Because the enterprises that can improve their capacity of clean production can transfer their permits to obtain additional income.

\section{Impose Environmental Taxes}

Solution to the issue of environmental pollution put forward by western mainstream economists is to adopt Pigovian tax that can correct the market economy mechanism. Pigou thinks that we can impose tax on polluter based on the environmental hazards caused by pollution, and use the tax to fill the balance between private cost and social costs to make the two equal, which will ultimately benefit the environment. The solution to the problem of market failure often relies on government intervention, so that the external cost can be internalized, which is proved to be a successful way by practice. From the early 1970s, the OECD Environmental Committee first proposed "polluter pays". In the 1980s, environmental taxes such as air pollution tax, water pollution tax, noise tax, solid waste tax and garbage tax and so on are widely imposed in western developed countries. Through the practical experience over 30 years, environment has been significantly improved in the developed countries because of the implementation of the environmental tax. For example, sulfur emissions in Sweden are reduced by nearly 6,000 tons due to the implementation of the sulfur tax; the decline in carbon dioxide emissions in some economic sectors of Norway is more than $20 \%$ per year thanks to the implementation of the carbon tax. Since the United States imposed a consumption tax on ozone-depleting chemicals, people have gradually reduced their consumption of Freon; the increase in the consumption of energy-efficient cars is due to the imposition of petrol taxes, thus reducing pollutant emissions; severance tax effectively curbed the exploitation of profit margins, thereby reducing the consumption of almost $10 \%-$ $15 \%$ of the total oil. [7]

\section{CONCLUSION}

Modern sustainable development is the sustainable development of three-dimensional composite system including ecological-economic-social as a whole, among which ecological persistence is the foundation, economic continuity is the condition and social persistence is the purpose. In the wave of globalization, foreign direct investment not only contributes greatly to economic growth, but also has an important impact on the natural environment. A considerable part of current theory of international trade and investment consider the pursuit of narrow comparative economic interests while ignore the broad sense of the social and ecological environment benefits. The final result is superficially the relevant countries made the so-called 
comparative interest through international economic activities. In fact, there is actually a party paying particularly high cost of the ecological environment, which may greatly exceed its economic benefits, and finally sacrifice its sustainable development. Therefore, under the guidance of the idea of sustainable development, efforts should be made to eliminate the negative impact of the use of foreign direct investment on the ecological environment and to promote the contribution to sustainable development made by using foreign direct investment, thus forming a virtuous circle.

In recent years, environmental pollution incidents are continuously exposed, which caused huge losses to the public life and property security, so environmental safety issues, especially industrial environmental pollution are attracting more and more attention, and people begin to question dereliction of duty of supervision department. This forced the government to pay attention to the governance of the environment. The government has introduced a series of laws and regulations to regulate corporate behavior, which is just a good trend. Public and the government have a certain demand for the environment, just as human beings go back to save the environment after damaging it when they just entered the industrial age. It is not too late that we recognize the consequences earlier now. And I believe that with the gradual increase of the awareness of the government and public, the environmental problems arising from the use of foreign direct investment will gradually diminish.

\section{REFERENCES}

[1] Huang Lujin, He Shiyou. Negative Effects of FDI on China 's Environment. Contemporary Economics (the second half of the month), 2008 (3).

[2] Chen Junya, Cai Jie. On the Influence of Foreign Investment on China 's Environmental Quality. Jianghan Tribune, 2013 (3).

[3] Zhang Deqiang. Conflict and Fusion of Foreign Direct Investment and Environmental Protection -- on How to Balance the Relationship between FDI and Environmental Protection in China. Journal of International Trade. 2007(9).

[4] Yu Feng, Qi Jianguo. An Empirical Study on the Environmental Effects of Foreign Direct Investment in China. Journal of International Trade, 2007 (8).

[5] Chen Shaoqiang, Cai Xiaoyan. Environmental Tax in Developed Countries and Its Enlightenment to China. China Development Observation, 2008 (7).

[6] Li Guozhu. Test of Causal Relationship between Foreign Direct Investment and Environmental Pollution. Journal of International Trade, 2007 (06).

[7] Song Xiuling, Zhao Yiwei, Meng Wenyan. Analysis on the Stage, Current Situation and Strategy of Foreign Direct Investment in China. Contemporary Economics, 2015(26).

[8] Teng Ying. Empirical Evidence of Foreign Direct Investment and Environmental Pollution. Entrepreneur World (theoretic edition), 2011 (14). 